\title{
Application of a posteriori granddaughter and modified granddaughter designs to determine Holstein haplotype effects ${ }^{1}$
}

\author{
J. I. Weller, ${ }^{2}$ P. M. VanRaden, $†$ and G. R. Wiggans $†$ \\ *Institute of Animal Sciences, A.R.O., The Volcani Center, Bet Dagan 50250, Israel \\ †Animal Improvement Programs Laboratory, Agricultural Research Service, US Department of Agriculture (USDA), Beltsville, MD 20705-2350
}

\begin{abstract}
A posteriori and modified granddaughter designs were applied to determine haplotype effects for Holstein bulls and cows with BovineSNP50 [ 50,000 single nucleotide polymorphisms (SNP); Illumina Inc., San Diego, CA] genotypes. The a posteriori granddaughter design was applied to 52 sire families, each with $\geq 100$ genotyped sons with genetic evaluations based on progeny tests. For 33 traits (milk, fat, and protein yields; fat and protein percentages; somatic cell score; productive life; daughter pregnancy rate; heifer and cow conception rates; service-sire and daughter calving ease; servicesire and daughter stillbirth; 18 conformation traits; and net merit), the analysis was applied to the autosomal segment with the SNP with the greatest effect in the genomic evaluation of each trait. All traits except 2 had a within-family haplotype effect. The same design was applied with the genetic evaluations of sons corrected for SNP effects associated with chromosomes besides the one under analysis. The number of within-family contrasts was 166 without adjustment and 211 with adjustment. Of the 52 bulls analyzed, 36 had BovineHD (high density; Illumina Inc.) genotypes that were used to test for concordance between sire quantitative trait loci and SNP genotypes; complete concordance was not obtained for any effects. Of the 31 traits with effects from the a posteriori granddaughter design, 21 were analyzed with the modified granddaughter design. Only sires with a contrast for the a posteriori granddaughter design and $\geq 200$ granddaughters with a record usable for genetic evaluation were included. Calving traits could not be analyzed because individual cow evaluations were not computed. Eight traits had within-family haplotype effects. With respect to milk and fat yields and fat percentage, the results on Bos taurus autosome
\end{abstract}

\footnotetext{
Received January 31, 2013.

Accepted April 22, 2013.

${ }^{1}$ The use of trade, firm, or corporation names in this publication is for the information and convenience of the reader. Such use does not constitute an official endorsement or approval by the US Department of Agriculture or the Agricultural Research Service of any product or service to the exclusion of others that may be suitable.

${ }^{2}$ Corresponding author: weller@agri.huji.ac.il
}

(BTA) 14 corresponded to the hypothesis that a missense mutation in the diacylglycerol O-acyltransferase 1 (DGAT1) gene is the main causative mutation, although other polymorphisms in that gene also modify fat yield and percentage. The positive allele for protein concentration was less frequent, which indicated that selection on that locus could be effective. Although the results can be used to determine causative polymorphisms for most of the analyzed traits, complete DNA sequencing of most of the analyzed sires probably will be required.

Key words: granddaughter design, genetic evaluation, genomic selection, haplotype

\section{INTRODUCTION}

Since 2008, genomic evaluation has become a reality chiefly because of the development of high-density SNP chips that allow for relatively inexpensive genotyping of individuals for tens of thousands of genetic markers. With thousands of genotyped bulls with progeny records, reliabilities of $>0.7$ can be obtained for genotyped animals without records or progeny records, compared with reliabilities of $<0.4$ based only on parent evaluations. The methods developed for genomic evaluations are based on population-wide linkage disequilibrium between closely linked markers and the actual QTL that determine phenotypes for the traits of interest (e. g., VanRaden et al., 2009). Because linkage disequilibrium is generally incomplete, even if a SNP has a major estimated effect on an economic trait, the SNP genotypes of individual animals do not necessarily correspond to their QTL genotypes. With the exception of the diacylglycerol O-acyltransferase 1 (DGAT1) and ATP-binding cassette sub-family G member 2 (ABCG2) genes (Grisart et al., 2002; Winter et al., 2002; Cohen-Zinder et al., 2005), quantitative trait nucleotides (QTN), which are the actual polymorphisms responsible for detected QTL, remain unknown. Determination of the actual polymorphisms responsible for the observed genetic variation should result in increased rates of genetic gain (Weller and Ron, 2011).

Methods applied to plants and experimental animals to determine QTN cannot be applied to large farm 
animals. For dairy cattle, the most convincing proof that a QTN has been discovered is if concordance is obtained for a sample of animals with known QTL genotypes. Complete concordance is obtained only if all individuals heterozygous for the QTL are also heterozygous for the putative QTN and vice versa. In addition, among the individuals heterozygous for the QTL, the allele with the positive effect on the trait should be associated with the same allele of the putative QTN (Ron and Weller, 2007). Proof that the QTN has been determined requires that concordance be ascertained for a sufficiently large group of animals so that the hypothesis that concordance was obtained by chance can be statistically rejected with high power (Ron and Weller, 2007).

Unlike major genes for which genotypes can be determined directly from the phenotypes, QTL genotypes can only be determined for bulls with many progeny based on application of either a daughter or granddaughter design (Weller et al., 1990). This design was first applied to the US dairy cattle population by Georges et al. (1995), and has since been applied to almost all major commercial dairy cattle populations (Weller, 2007).

Weller and Ron (2011) proposed application of a posteriori granddaughter design (APGD), diagrammed in Figure 1A, to determine QTL genotypes for bulls from large populations of individuals genotyped using high-density SNP chips. Similar to the original granddaughter design, sires with many progeny-tested sons are analyzed. However, rather than genotype the sons specifically for application of a granddaughter design, the data generated by genotyping many bulls for highdensity SNP chips are used. Thus, the design is considered a posteriori. The sons of each bull are divided into 2 groups based on which paternal haplotype was passed to each son for the chromosomal region with the putative QTL. If a contrast $(P<0.05)$ is obtained between the 2 progeny groups, then it can be deduced that the sire is heterozygous for the QTL. Otherwise, it can be assumed that the sire is homozygous for the QTL, provided that the experimental design has sufficient power to detect heterozygous sires with a high probability.

Compared with application of granddaughter designs based on microsatellites, the a posteriori design is more powerful for genomic analysis for several reasons. First, unlike individual microsatellites, which are homozygous for a significant fraction of the animals' genotypes, in the APGD, each haplotype is based on the genotypes of tens of tightly linked SNP (e. g., Druet et al., 2008). Many different haplotypes segregate in the population for each specific chromosomal segment, and almost all bulls are heterozygous for their haplotypes. Thus, the paternal haplotype of almost all sons can be determined. Second, the bulls available for analysis in the 1990s were a selected sample, as semen of inferior bulls was generally not retained by the AI institutes. Finally, if the whole genome is analyzed, then the number of individual comparisons is huge, and nominal significance levels of 5 or $1 \%$ are meaningless. Thus, much lower nominal significance levels are required to determine that a segregating QTL has been detected. In the current study, this multiple comparison problem was avoided by considering only specific chromosomal regions that were shown to harbor segregating QTL by genome scan results.

Weller et al. (2002) proposed that QTL allelic frequencies and the number of segregating QTL alleles in the population could be determined by application of a modified granddaughter design. In this design, diagrammed in Figure 1B, maternal granddaughters of a bull are divided into 3 groups based on which grandpaternal haplotype was passed to each granddaughter. Based on Mendelian sampling, 25\% of the granddaughters should receive 1 of the 2 grandpaternal alleles, $25 \%$ should receive the other allele, and the remaining $50 \%$ should receive neither allele. Similar to the APGD for genomic evaluation, almost all grandsires will be heterozygous for their haplotypes, and haplotype determination of the granddaughters can be determined almost without error. The main advantage of the modified granddaughter design is that those granddaughters that received neither grandpaternal haplotype can be considered to be a random sample of the QTL alleles that are segregating in the population. Thus, by comparing the effects associated with the 2 grandpaternal haplotypes with the effect associated with the granddaughters that received neither grandpaternal allele, determining the relative frequencies of the 2 grandpaternal QTL alleles in the population should be possible (Weller et al., 2002). The closer the effect associated with 1 grandpaternal QTL allele is to the effect associated with neither grandpaternal allele, the greater the frequency of this allele in the general population. Determining if more than 2 effective QTL alleles are segregating in the population also should be possible (i.e., alleles with measurably different effects on the trait). This will be observed if the effects of the 2 paternal alleles relative to the progeny group that received neither paternal allele differ $(P<0.05)$ across families (Weller et al., 2002).

The primary objective of this study was to determine QTL genotypes for chromosomal regions determined previously to harbor segregating QTL for all traits that are genetically evaluated in the United States for a sample of approximately 50 bulls via application of the APGD. These data were then used to determine 

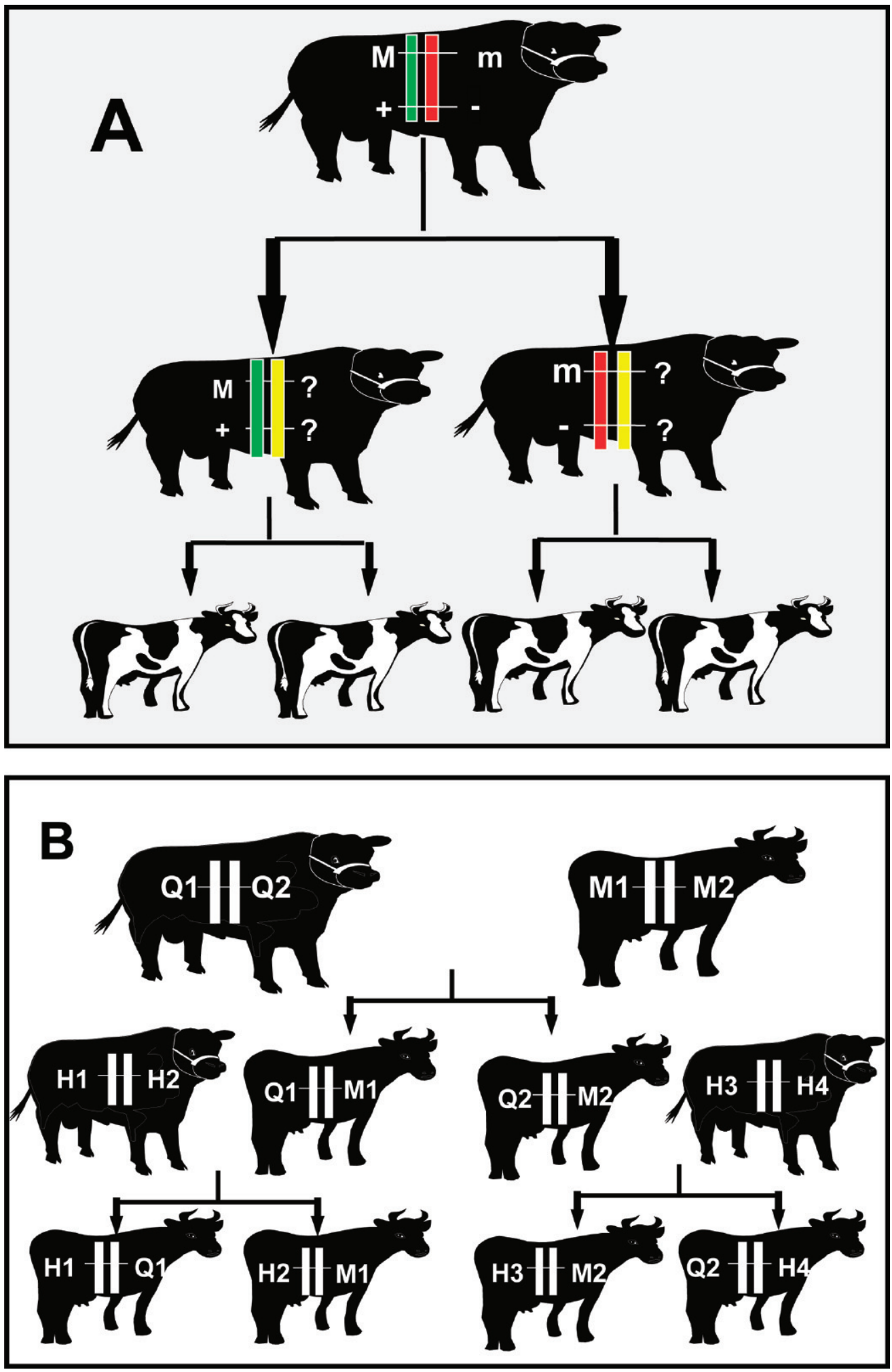

Figure 1. (A) Illustration of the a posteriori granddaughter design. In this design, genotypes of the paternal sons and their genetic evaluations based on their daughter records are analyzed. A single chromosome is shown. The 2 haplotypes are denoted "M" and "m," and the QTL effects are denoted "+" and "-." (B) Illustration of the modified granddaughter design. In this design, the genotypes and genetic evaluations of the maternal granddaughters based on their own records are analyzed. The QTL alleles of the grandsire are denoted "Q1" and "Q2"; QTL effects derived from other male ancestors are denoted "H1," "H2," "H3," and "H4"; and QTL effects derived from female ancestors are denoted "M1" and "M2." Color version available in the online PDF. 
concordance for the SNP included on the BovineHD BeadChip (high density; Illumina Inc., San Diego, CA). The secondary objective was to apply the modified granddaughter designs to a large sample of Holstein bulls and cows, to confirm the results of the APGD and to estimate QTL allelic frequencies.

\section{MATERIALS AND METHODS}

\section{Animals Analyzed}

A total of 19,365 Holstein bulls with an August 2012 US Department of Agriculture-DHIA genetic evaluation based on $\geq 10$ daughters and with a BovineSNP50 ( 50,000 SNP; Illumina Inc.) genotype were selected for analysis. In addition to US bulls, the sample also included Canadian, Italian, and UK bulls. For application of the APGD, 9,180 bulls that were sons of 52 bulls with $\geq 100$ sons per sire were retained. The number of sons per sire ranged from 100 to 608 for milk production traits (Table 1). Sire families were deleted from analysis of individual traits if the sire was homozygous for the specific haplotype region analyzed. Similarly, sons of a sire were deleted if they were homozygous for a single haplotype or if a son received neither of his sire's haplotypes. This could occur because of crossovers within the haplotype, genotyping mistakes, or incorrect phasing. Thus, the specific number of bulls in each analysis varied as a function of the specific chromosomal region analyzed. Genomic evaluations were analyzed, but they were expected to be very similar to traditional genetic evaluations computed with a standard animal model (VanRaden and Wiggans, 1991), because each son was required to have $\geq 10$ daughters with a record usable for genetic evaluation.

Of 233,482 genotyped Holsteins in the US database, 165,540 were female, but only 27,704 were cows with a lactation record usable for genetic evaluation of milk production traits. This was determined by comparing the reliability of the cows' traditional PTA with the reliability of the cows' traditional parent average. If the difference was $>5 \%$, the cow was assumed to have $\geq 1$ lactation record usable for genetic evaluation. Traditional PTA were analyzed because of the relatively greater effect of genotype information on genomic cow evaluations (i.e., the effect of specific SNP could overwhelm phenotypic data). For fertility traits, which have lower heritability, a difference of $>2 \%$ was required for inclusion. It should be noted though that these cows are a selected sample with overrepresentation of elite cows. Adjustments of Wiggans et al. (2011) were applied to reduce bias in cow PTA and make their statistical properties more similar to bull PTA.
In the modified granddaughter analysis for each trait, only granddaughters of bulls heterozygous for the QTL effect as determined by the APGD were included. In addition, grandsire families were deleted if the number of genotyped granddaughters per grandsire was $<200$. A larger sample was required for this analysis because 3 within-grandsire classes were defined, compared with 2 for the APGD, and because reliabilities for cow evaluations are lower than for bull evaluations. The number of granddaughters with a lactation record usable for genetic evaluation ranged from 9 to 1,776 for milk production traits (Table 1 ). Note that these are the maternal granddaughters, not the paternal granddaughters, and include only granddaughters with genotypes. Only 18 bulls had $\geq 200$ granddaughters. As in the APGD, individual granddaughter records were deleted if the granddaughter was homozygous for the grandsire haplotype.

\section{Genotype and Haplotype Determination}

Details of the US genomic evaluation system for dairy cattle have been reported by VanRaden et al. (2009). Of the 54,001 SNP in the original Illumina BovineSNP50 Genotyping BeadChip and the 54,609 SNP in version 2 (Illumina Inc., 2011), 45,178 were retained for analysis. Haplotypes were determined using the findhap.f90 Fortran program (VanRaden, 2011). Each haplotype segment included a maximum of 75 markers, with the exact number of markers adjusted to achieve almost equal numbers of markers per segment within chromosome. The 75-marker length was chosen to maximize accuracy of imputation from less-dense chips. Longer segments also are used in the imputation program, but shorter segments resulted in haplotypes containing too few markers for low-density chips. Over the entire genome, there were 617 haplotype segments.

Of the 52 bulls analyzed, 36 had BovineHD genotypes (Table 1). Although the Illumina BovineHD Genotyping BeadChip includes 777,962 SNP (Illumina Inc., 2010), a large portion of those markers were found to be redundant. Thus, only 311,725 markers were retained for analysis.

\section{Traits Analyzed}

Thirty-three traits that are included in the US genetic evaluation system (VanRaden et al., 2007) were analyzed: 5 milk production traits (milk, fat, and protein yields and fat and protein percentages); SCS; productive life; 3 fertility traits (daughter pregnancy rate and heifer and cow conception rates); 4 calving traits (service-sire and daughter calving ease, and service-sire and daughter stillbirth; Van Tassell et al., 
Table 1. Numbers of sons, granddaughters with a lactation record usable for genetic evaluation for milk production traits, and significant $(P<0.01)$ contrasts per sire computed from evaluations with the SNP with the greatest effect adjusted for SNP effects on other chromosomes for 52 Holstein bulls

\begin{tabular}{|c|c|c|c|c|}
\hline Bull & $\begin{array}{l}\text { High-density } \\
\text { genotype available }\end{array}$ & $\begin{array}{l}\text { Sons } \\
\text { (no.) }\end{array}$ & $\begin{array}{c}\text { Granddaughters } \\
\text { (no.) }\end{array}$ & $\begin{array}{c}\text { Contrasts } \\
\text { (no.) }\end{array}$ \\
\hline 1 & No & 109 & 105 & 0 \\
\hline 2 & Yes & 100 & 51 & 4 \\
\hline 3 & Yes & 121 & 9 & 0 \\
\hline 4 & Yes & 165 & 460 & 7 \\
\hline 5 & Yes & 134 & 835 & 8 \\
\hline 6 & No & 121 & 16 & 5 \\
\hline 7 & No & 193 & 229 & 11 \\
\hline 8 & Yes & 177 & 218 & 4 \\
\hline 9 & Yes & 225 & 221 & 7 \\
\hline 10 & No & 193 & 45 & 4 \\
\hline 11 & No & 448 & 1,135 & 4 \\
\hline 12 & Yes & 230 & 487 & 3 \\
\hline 13 & Yes & 165 & 116 & 6 \\
\hline 14 & Yes & 101 & 58 & 1 \\
\hline 15 & Yes & 131 & 188 & 3 \\
\hline 16 & Yes & 608 & 1,776 & 5 \\
\hline 17 & Yes & 129 & 196 & 3 \\
\hline 18 & Yes & 103 & 89 & 3 \\
\hline 19 & Yes & 129 & 10 & 5 \\
\hline 20 & Yes & 205 & 58 & 3 \\
\hline 21 & No & 123 & 16 & 9 \\
\hline 22 & No & 248 & 68 & 2 \\
\hline 23 & No & 100 & 96 & 0 \\
\hline 24 & Yes & 142 & 72 & 2 \\
\hline 25 & Yes & 119 & 100 & 4 \\
\hline 26 & Yes & 117 & 77 & 7 \\
\hline 27 & Yes & 104 & 52 & 2 \\
\hline 28 & Yes & 155 & 114 & 4 \\
\hline 29 & Yes & 104 & 1,116 & 5 \\
\hline 30 & Yes & 110 & 24 & 5 \\
\hline 31 & Yes & 105 & 58 & 7 \\
\hline 32 & Yes & 203 & 493 & 3 \\
\hline 33 & Yes & 135 & 58 & 3 \\
\hline 34 & Yes & 103 & 72 & 5 \\
\hline 35 & Yes & 105 & 83 & 3 \\
\hline 36 & Yes & 247 & 296 & 5 \\
\hline 37 & No & 352 & 403 & 1 \\
\hline 38 & No & 153 & 193 & 2 \\
\hline 39 & No & 222 & 240 & 2 \\
\hline 40 & Yes & 402 & 1,772 & 8 \\
\hline 41 & Yes & 384 & 274 & 7 \\
\hline 42 & Yes & 202 & 484 & 6 \\
\hline 43 & Yes & 100 & 91 & 3 \\
\hline 44 & No & 144 & 162 & 5 \\
\hline 45 & Yes & 100 & 25 & 0 \\
\hline 46 & No & 121 & 174 & 6 \\
\hline 47 & No & 122 & 77 & 5 \\
\hline 48 & No & 148 & 269 & 2 \\
\hline 49 & Yes & 259 & 157 & 3 \\
\hline 50 & Yes & 204 & 263 & 3 \\
\hline 51 & No & 123 & 18 & 2 \\
\hline 52 & Yes & 137 & 106 & 4 \\
\hline
\end{tabular}

2003; Cole et al., 2007); 18 conformation traits [stature, strength, body depth, dairy form, rump angle, thurl width, rear legs (side view), rear legs (rear view), foot angle, feet and legs score, fore udder attachment, rear udder height, rear udder width, udder cleft, udder depth, front teat placement, rear teat placement, and teat length)], which are evaluated by Holstein Association USA (2012; Brattleboro, VT); and the net merit genetic-economic index (Cole et al., 2010). Of the 3 fertility rates, cow conception rate and daughter pregnancy rate both measure cow fertility and are highly correlated (VanRaden et al., 2011).

\section{Statistical Analyses}

For each trait, the haplotype segment containing the autosomal SNP associated with the greatest effect 
in the genomic analysis of the complete population (VanRaden et al., 2009) was selected for analysis by the APGD. Single nucleotide polymorphisms located on the sex chromosome were not analyzed because all sons received the $\mathrm{Y}$ chromosome of their sire. Even for SNP located on the pseudoautosomal region of the $\mathrm{X}$ chromosome, approximately $80 \%$ of all sons received the sire's paternal haplotype, which is attached to the Y chromosome.

The statistical model was

$$
Y_{i j k}=S_{i}+H_{i j}+e_{i j k}
$$

where $Y_{i j k}$ is the genetic evaluation of bull $k$, which is a son of sire $i$ that received sire haplotype $j ; S_{i}$ is the effect of sire $i ; H_{i j}$ is the effect of haplotype $j$ of sire $i$; and $e_{i j k}$ is the random residual associated with each evaluation. Analysis of this model was by PROC GLM of SAS (SAS Institute, 2012). Overall haplotype effect $(P<0.05)$ indicates that a QTL is segregating within the haplotype segment or in close proximity. A specific within-family haplotype effect $(P<0.05)$ indicates that the specific bull is segregating for the QTL. This model does not account for maternal relationships among the sons (e.g., sons that have the same dam or maternal granddam). However, the effect of these relationships on QTL segregating among the sires should be minimal.

For overall haplotype effect $(P<0.05)$, the design was applied with a shift of 1 haplotype segment to the left and then to the right. If the $F$-value for the haplotype effect was increased, then the analysis was again performed with the haplotype shifted another unit in the direction that resulted in an increase in the $F$-value. This procedure was continued until a smaller $F$-value was obtained or the end of the chromosome was reached.

The APGD was reapplied to the haplotype segment with the greatest $F$-value and to the haplotype segment containing the SNP with the greatest effect, but with the genetic evaluation of each bull corrected for the effects of all chromosomes except the one under analysis. To compute an adjusted evaluation, the genetic evaluation was first deregressed, and then effects associated with each chromosome (other than the one under analysis) were subtracted. Subtraction of SNP effects from all other chromosomes should be more accurate than including either a genomic or pedigree relationship matrix, because the SNP effects were estimated from the entire data and not just the selected families.

For each trait with a haplotype effect $(P<0.05)$ for the APGD, concordance was examined between the trait effects and the sires' marker genotypes for the 30 markers closest to the marker on either side with the greatest effect. If the segment with the greatest effect was not the original segment with the marker with the greatest effect, then the 30 markers analyzed were those in the segment with the greatest $F$-value closest to the segment with the marker with the greatest effect. Concordance per bull was assumed if either of the following conditions was met: (1) the absolute $t$-value of the within-family contrast was $<2$ and the marker was homozygous, or (2) the absolute $t$-value of the within-family contrast was $>3$ and the marker was heterozygous. If the $t$-value was between 2 and 3 or the genotype of the sire was not determined for the specific SNP, then concordance was considered to be undetermined. These criteria were chosen because $5 \%$ of the bulls $(\sim 2.5)$ could be expected to have absolute $t$-values $>2$ by chance, but only $0.26 \%$ of the bulls $(\sim 0.14)$ should have $t$-values $>3$. It should be noted though that a $t$-value $<2$ does not prove that the bull is homozygous. All that can be determined is that the null hypothesis of no difference between the means could not be rejected. Concordance was considered to be complete if it could not be rejected for any of the bulls included in the APGD analysis with valid genotypes and absolute $t$-values of $<2$ or $>3$.

The modified granddaughter design was applied to the traits with an overall $F$-value $(P<0.01)$ for the haplotype effect in the APGD except for the 4 calving traits, because those traits did not have individual cow evaluations. The analysis model for the modified design was the same as for the a posteriori design, except that the dependent variable was the granddaughters' evaluations and the independent variables were the grandsire effect and the haplotype effect nested within grandsire. Instead of 2 haplotype classes for each sire in the APGD, there were 3 classes in the modified granddaughter design; the third class included granddaughters that received neither grandsire haplotype. Only grandsires with haplotype effects ( $t$-values with absolute values of $>3$ ) and $\geq 200$ granddaughters with a record usable for genetic evaluation were included in the analyses. As in the APGD, no correction was made for relationships other than those included in the analysis model.

\section{RESULTS AND DISCUSSION}

Of the 33 traits analyzed, the SNP with the greatest effect overall was located on an autosome for 27 traits (Table 2). Within-family haplotype had an effect $(P<$ 0.001 ) for all of those traits [rear legs (rear view) and rear teat placement $(P<0.01)]$. For final score, dairy form, foot angle, rear legs (rear view), feet and legs score, and rear udder height, the SNP with the greatest effect was on the sex chromosome. Within-family hap- 
lotype with the SNP with the greatest autosomal effect also had an effect for final score, dairy form, and foot angle $(P<0.001)$ and rear legs (rear view; $P<0.01$ ). Paternal haplotype did not have an effect $(P>0.05)$ for feet and legs score and rear udder height. Thus, almost all the SNP analyzed do represent chromosomal regions containing segregating QTL that can be detected by the APGD.

The numbers of families with contrasts $(P<0.001)$ and mean value of those contrasts for haplotypes with the SNP with the greatest effect without adjustment for SNP effects on other chromosomes are shown in Table 2 as are the mean absolute $t$-values for those contrasts, ratios of mean family contrast value to greatest individual SNP effect for population, and locations of the haplotype segment with the greatest $F$-value relative to the haplotype segment with the SNP with the greatest effect. The contrast values and SNP effects are given in breeding value units, which correspond to QTL substitution effects. For all traits, mean family contrast was greater than SNP effect, with a mean ratio of 5.1. The haplotype effect is expected to be larger than the SNP effect, which is a function of linkage disequilibrium over the population, does not completely correspond to the genotypes for the causative mutation, and should, therefore, be smaller than the actual QTL effect. Furthermore, several adjacent SNP may share the QTL effect. However, the mean haplotype effect was biased upwards, because only effects with a $t$-value of $>3$ were included. Therefore, some sires that were heterozygous

Table 2. Numbers of families with significant $(P<0.001)$ contrasts and mean value of those contrasts for haplotypes with SNP with the greatest effects without adjustment for SNP effects on other chromosomes by trait and autosomal chromosome location

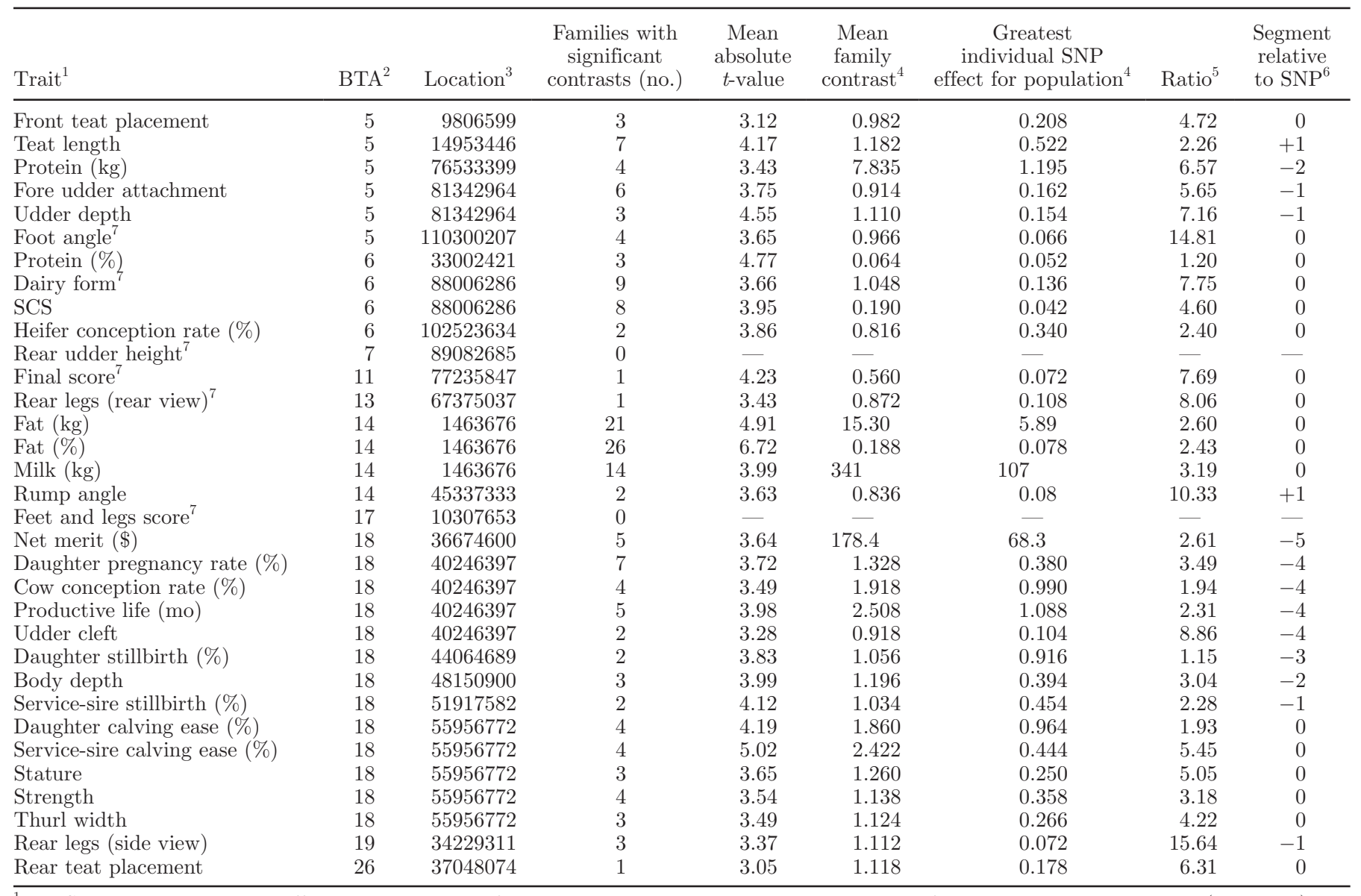

\footnotetext{
${ }^{1}$ The SNP with the greatest effect overall was significant at $P<0.001$ on an autosomal seg

${ }^{2}$ Bos taurus autosome.

${ }^{3}$ Beginning of haplotype segment with greatest $F$-value.

${ }^{4}$ The contrast values and SNP effects are given in breeding value units, which correspond to QTL substitution effects.

${ }^{5}$ Mean family contrast:greatest individual SNP effect for population.

${ }^{6}$ Relative location of haplotype segment with greatest $F$-value relative to haplotype segment with SNP with the greatest effect.

${ }^{7}$ The SNP with the greatest effect was on the sex chromosome.
} 
for the QTL (but with relatively smaller contrasts) may have been deleted.

Overall, 166 within-family contrasts $(P<0.001)$ with a $t$-value of $>3$ resulted in a mean of 5.0 significant effects per trait. A single SNP on BTA18 was the SNP with the greatest effect for 13 of the 31 traits with haplotype effects $(P<0.01)$. The major effects associated with this SNP have been documented by Cole et al. (2009). However, for 8 of those traits, the haplotype segment with the greatest effect was upstream of the segment containing the SNP; for net merit, the haplotype segment was upstream by 5 segments (almost $20 \mathrm{Mbp}$ ). For 6 other traits that had the haplotype segment with the greatest effect on other chromosomes, that segment did not contain the SNP with the greatest effect. A QTL affecting daughter pregnancy rate near $45 \mathrm{Mbp}$ on BTA18 was previously detected by Ashwell et al. (2004). The 3 traits with the greatest number of families with contrasts $(P<0.001)$ were fat percentage (26), fat yield (21), and milk yield (24). That finding was not surprising, because the analyzed chromosomal segment contained the DGAT1 gene on BTA 14, which has been shown to have a major effect on those traits (Grisart et al., 2002; Winter et al., 2002). The SNP and haplotype segments with the greatest effects on protein percentage are closely linked to a polymorphism in the $A B C G 2$ gene on BTA 6 , which has been proposed as the causative mutation for that effect (Cohen-Zinder et al., 2005).

Results that correspond to the information in Table 2 are shown in Table 3 after adjustment of SNP with the greatest effects for the effects of SNP on other chromosomes. Generally, the residual variance after adjustment for all other chromosomes was only about $25 \%$ of the residual variance without adjustment. Thirtyone traits had within-family effects $(P<0.001)$ with adjustment. Feet and legs score again did not have a within-family effect $(P>0.05)$ with adjusted evaluations. In addition, even though heifer conception rate had a within-family effect $(P<0.05)$ with adjustment, none of the individual families had a $t$-value of $>3$. The total number of within-family contrasts was 211 (compared with 166 without adjustment), and mean number of significant effects per trait was 6.4 (compared with 5.0 without adjustment). As expected, mean family contrasts were lower than without adjustment, because a $t$-value of 3 was obtained for a smaller effect. The mean ratio of haplotype to SNP effects was only 3.4 (compared with 5.1 without adjustment), and 3 traits (protein percentage, dairy form, and service-sire calving ease) had ratios of $<1.00$. The haplotype segment with the greatest effect was the same as without adjustment for all traits except protein yield. For that trait, the haplotype segment with the SNP with the greatest effect also had the greatest $F$-value with adjustment.

Of the 52 bulls analyzed, only 4 had no contrasts $(P<0.001)$ with adjustment (Table 1$)$. Those 4 bulls had between 100 and 121 sons. Thus, the relatively low number of sons for those bulls may be a factor in the lack of significant haplotype contrasts. The bull with the greatest number of contrasts segregated for 11 traits and had 193 sons; another bull (123 sons) segregated for 9 traits. The mean number of contrasts per bull (excluding the 4 bulls with no contrasts) was 4.4 .

The current study is much more extensive than previous granddaughter design analyses, both in the number of animals included in the analysis and the number of traits analyzed. For example, Georges et al., (1995) analyzed 1,518 sons of 14 sires for the 5 milk production traits. Ashwell et al. (2004) analyzed 1,415 sons of 10 sires for the 5 milk production traits, pregnancy rate, SCS, and productive life. Thus, 6 times as many sons and 3 to 5 times as many families were included in the current analysis. Also, because relatively long haplotypes were defined, almost all sires were heterozygous, and the origin of the sons' haplotypes could be determined in almost all cases. Finally, as noted by Georges et al. (1995), previous granddaughter design analyses were based on selected samples, because semen of inferior bulls was not retained, which resulted in underestimates of effects for traits that underwent major selection. This is no longer the case for the current data set. These factors should explain the fact that significance was obtained for almost all traits.

Complete concordance was not obtained for any of the traits analyzed either with or without adjustment. Thus, the QTN was not among the BovineHD SNP for any of the traits. For all traits, $\geq 5$ bulls were nonconcordant. Thus, as postulated by Ron and Weller (2007), the probability of obtaining concordance by chance with a sample of this size is very small. It is not too surprising that complete concordance was not obtained because even the BovineHD BeadChip includes only a small fraction of the total DNA variation. Thus, complete DNA sequencing will probably be required to determine the QTN for these QTL. Even though the 2 QTN determined to date are missense mutations, this of course is not necessarily the case for all QTL. Many genes are functionally multiallelic; for example, $\alpha-\mathrm{CN}$. In addition, the observed effect could be due to copy number variation (e.g., Glick et al., 2011). If the genetic variation at a specific QTL is controlled by multiple polymorphisms or a more complicated mechanism, then it may not be possible to determine concordance.

Results of the modified granddaughter design for traits with within-family effects $(P<0.01)$ for the 
Table 3. Numbers of families with significant $(P<0.001)$ contrasts and mean value of those contrasts for haplotypes with SNP with the greatest effects after adjustment for SNP effects on other chromosomes by trait and autosomal chromosome location

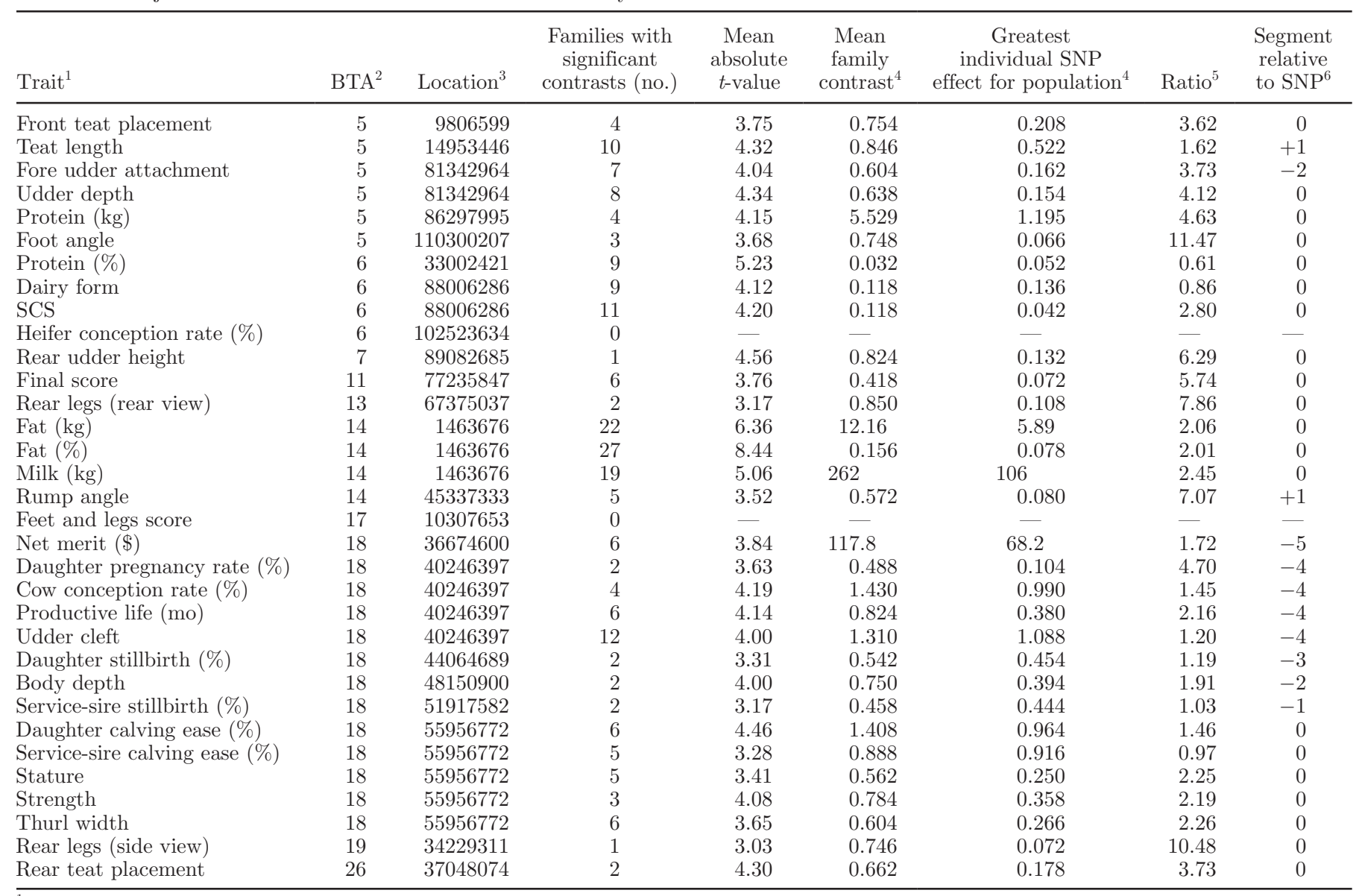

${ }^{1} \mathrm{SNP}$ with the greatest effect overall was significant at $P<0.001$ on an autosomal segment for all traits except heifer conception rate $(P<0.05$; no families with $t$-value of $>3)$ and feet and legs score $(P>0.05)$.

${ }^{2}$ Bos taurus autosome.

${ }^{3}$ Beginning of haplotype segment with greatest $F$-value.

${ }^{4}$ The contrast values and SNP effects are given in breeding value units, which correspond to QTL substitution effects.

${ }^{5}$ Mean family contrast:greatest individual SNP effect for population.

${ }^{6}$ Relative location of haplotype segment with greatest $F$-value relative to haplotype segment with SNP with the greatest effect.

APGD applied to unadjusted evaluations are shown in Table 4. Front teat placement, heifer conception rate, body depth, stature, and rear teat placement were not analyzed because none of the grandsire families with contrasts had $\geq 200$ daughters with records usable for genetic evaluation; as noted previously, the 4 calving traits were not analyzed because genetic evaluations were not computed for individual cows. Of the 23 traits analyzed, foot angle, dairy form, SCS, final score, rear legs (rear view), rump angle, net merit, udder cleft, daughter pregnancy rate, productive life, strength, thurl width, and rear legs (side view) did not have withinfamily contrasts $(P>0.05)$ for the modified grandsire design. However, this design is less powerful than the APGD, even though a minimum of 200 granddaughters per family was required. The granddaughter records have much lower reliability than the sons' evaluation, which were required to have PTA based on at least 10 daughter records. Finally, as noted previously, the cows are not a random sample of daughters, which results in biased estimates of the QTL effect, as noted by Georges et al. (1995).

Within-family contrasts and their standard errors are shown in Table 4 in order of haplotype chromosomal location for teat length, protein yield, fore udder attachment, udder depth, protein percentage, fat yield, fat percentage, and milk yield. Of the 28 family-trait combinations analyzed, only 5 (4 for fat yield and 1 for fore udder attachment) within-family contrasts were not significant $(P>0.05)$. Thus, the results of analyses 
Table 4. Contrasts within family from application of a modified granddaughter design to traits with withinfamily effects $(P<0.01)$ from application of an a posteriori granddaughter design to unadjusted evaluations by trait and grandsire

\begin{tabular}{|c|c|c|c|c|}
\hline Trait & Grandsire & $\begin{array}{c}\text { Granddaughters } \\
\text { (no.) }\end{array}$ & $\begin{array}{l}\text { Grandpaternal } \\
\text { haplotype }\end{array}$ & Contrast $^{1}$ \\
\hline \multirow[t]{2}{*}{ Teat length*** } & \multirow[t]{2}{*}{16} & \multirow[t]{2}{*}{1,183} & 1 & $0.482 \pm 0.126^{* * *}$ \\
\hline & & & 2 & $-0.308 \pm 0.132^{*}$ \\
\hline \multirow[t]{2}{*}{ Protein $(\mathrm{kg})^{* *}$} & \multirow[t]{2}{*}{48} & \multirow[t]{2}{*}{258} & 1 & $0.156 \pm 2.043$ \\
\hline & & & 2 & $-7.675 \pm 2.148^{* * *}$ \\
\hline \multirow[t]{8}{*}{ Fore udder attachment*** } & \multirow[t]{2}{*}{4} & \multirow[t]{2}{*}{277} & 1 & $0.834 \pm 0.292^{* *}$ \\
\hline & & & 2 & $0.130 \pm 0.244$ \\
\hline & \multirow[t]{2}{*}{32} & \multirow[t]{2}{*}{411} & 1 & $-0.548 \pm 0.198^{* *}$ \\
\hline & & & 2 & $0.086 \pm 0.226$ \\
\hline & \multirow[t]{2}{*}{40} & \multirow[t]{2}{*}{993} & 1 & $0.380 \pm 0.124^{* *}$ \\
\hline & & & 2 & $0.048 \pm 0.150$ \\
\hline & \multirow[t]{2}{*}{41} & \multirow[t]{2}{*}{208} & 1 & $0.174 \pm 0.314$ \\
\hline & & & 2 & $-0.502 \pm 0.298$ \\
\hline \multirow[t]{4}{*}{ Udder depth*** } & \multirow[t]{2}{*}{4} & \multirow[t]{2}{*}{277} & 1 & $0.954 \pm 0.286^{* * *}$ \\
\hline & & & 2 & $0.038 \pm 0.240$ \\
\hline & 40 & 993 & 1 & $0.324 \pm 0.122^{* *}$ \\
\hline & & & 2 & $-0.030 \pm 0.148$ \\
\hline Protein $(\%)^{* *}$ & 11 & 1,061 & 1 & $0.0139 \pm 0.0044^{* *}$ \\
\hline & & & 2 & $-0.0002 \pm 0.0042$ \\
\hline Fat $(\mathrm{kg}) * * *$ & 4 & 380 & 1 & $-4.100 \pm 2.164$ \\
\hline & & & 2 & $0.818 \pm 2.173$ \\
\hline & 5 & 779 & 1 & $5.073 \pm 1.418^{* * *}$ \\
\hline & & & 2 & $0.418 \pm 1.682$ \\
\hline & 7 & 215 & 1 & $-1.136 \pm 2.818$ \\
\hline & & & 2 & $0.864 \pm 3.118$ \\
\hline & 16 & 1,603 & 1 & $2.673 \pm 1.009^{* *}$ \\
\hline & & & 2 & $-1.882 \pm 1.118$ \\
\hline & 40 & 1,621 & 1 & $-0.382 \pm 0.973$ \\
\hline & & & 2 & $-0.455 \pm 1.182$ \\
\hline & 42 & 424 & 1 & $5.718 \pm 1.936^{* *}$ \\
\hline & & & 2 & $-2.900 \pm 2.245$ \\
\hline & 50 & 246 & 1 & $2.000 \pm 2.818$ \\
\hline & & & 2 & $-4.864 \pm 2.882$ \\
\hline Fat $(\%)^{* * *}$ & 4 & 380 & 1 & $-0.0704 \pm 0.0158^{* * *}$ \\
\hline & & & 2 & $0.0222 \pm 0.0158$ \\
\hline & 5 & 779 & 1 & $0.0824 \pm 0.0104^{* * *}$ \\
\hline & & & 2 & $-0.0154 \pm 0.0122$ \\
\hline & 7 & 215 & 1 & $-0.0502 \pm 0.0204^{*}$ \\
\hline & & & 2 & $0.0478 \pm 0.0226^{*}$ \\
\hline & 12 & 387 & 1 & $0.1066 \pm 0.0156^{* * *}$ \\
\hline & & & 2 & $0.0416 \pm 0.0160^{*}$ \\
\hline & 16 & 1,603 & 1 & $0.0226 \pm 0.0074^{* *}$ \\
\hline & & & 2 & $-0.0210 \pm 0.0021^{* *}$ \\
\hline & 40 & 1,621 & 1 & $0.0168 \pm 0.0070^{*}$ \\
\hline & & & 2 & $-0.0144 \pm 0.0086$ \\
\hline & 42 & 424 & 1 & $0.0910 \pm 0.0140^{* * *}$ \\
\hline & & & 2 & $-0.0444 \pm 0.0164^{* *}$ \\
\hline & 50 & 246 & 1 & $0.0616 \pm 0.0204^{*}$ \\
\hline & & & 2 & $-0.0080 \pm 0.0210$ \\
\hline Milk (kg)*** & 5 & 779 & 1 & $-133 \pm 38^{* * *}$ \\
\hline & & & 2 & $60 \pm 45$ \\
\hline & 12 & 387 & 1 & $-257 \pm 58^{* * *}$ \\
\hline & & & 2 & $38 \pm 60$ \\
\hline & 42 & 424 & 1 & $-149 \pm 62^{* *}$ \\
\hline & & & 2 & $72 \pm 61$ \\
\hline & 50 & 246 & 1 & $-153 \pm 67^{*}$ \\
\hline & & & 2 & $-110 \pm 78$ \\
\hline
\end{tabular}

${ }^{1}$ Relative to granddaughter group that inherited neither grandpaternal allele. The contrast values are given in breeding value units, which correspond to QTL substitution effects.

${ }^{*} P<0.05 ;{ }^{*} P<0.01 ;{ }^{* * *} P<0.001$.

using both granddaughter designs confirmed the hypothesis that the SNP with the greatest effects in the genomic analysis actually represent segregating QTL that can be detected by those designs. The magnitudes of the contrasts are expected to be smaller for cows, because, as noted previously, the animals genotyped were 
a selected sample; and cow evaluations are more highly regressed than bull evaluations (Ron et al., 2004).

For teat length, protein yield, and protein percentage, only 1 family was analyzed for each trait. Thus, ascertaining if $>2$ effective alleles are segregating was not possible for those traits. For all 3 traits, the effect associated with 1 grandpaternal haplotype was positive, and the effect associated with the other grandpaternal allele was negative, which is expected if only 2 QTL alleles are segregating in the population. For teat length and protein percentage, the absolute value was greater for the positive allele, which indicated that it was the less-frequent allele. Thus, selection on those loci could be effective. For protein yield, the absolute value was greater for the negative allele, and selection on that locus would not be very effective. The grandsire analyzed for protein percentage probably did not segregate for the QTN found previously in the $A B C G 2$ gene (Cohen-Zinder et al., 2005). The magnitude of the effect associated with that QTN is an order of magnitude greater than the effect shown in Table 4.

Three of the 4 bulls analyzed for fore udder attachment had significant $(P<0.01)$ within-family contrasts. However, the direction and magnitude of the effects was not consistent. For 2 bulls, both alleles had positive effects, and the allele with the greater effect was significant $(P<0.01)$. For the third bull, 1 allele had a positive effect and the other a negative effect, and the absolute value was greater for the negative allele. For this chromosomal region, $>2$ effective QTL alleles likely segregated. Similar inconsistencies were found for the 2 bulls analyzed for udder depth, which has haplotypes in the same chromosomal region.

Of the 7 bulls analyzed for fat yield, 3 had significant $(P<0.01)$ contrasts. For all of those bulls, the effect of the positive allele was significant $(P<0.01)$, whereas the other allele was not different $(P>0.05)$ from the bulls that received neither grandpaternal allele. Thus, the positive allele is apparently the less frequent allele, which corresponds to the results of Kaupe et al. (2004), who estimated the frequencies of the 2 DGAT1 alleles in various populations.

For 7 of the 8 bulls analyzed for fat percentage, 1 haplotype had a positive effect, and the other haplotype had a negative effect. The absolute value for the allele with the positive effect allele was greater than for the allele with the negative effect for 6 of those bulls; thus, the allele with the positive effect is apparently the less frequent allele, which corresponds to the results of Kaupe et al. (2004). However, the results for the other family indicate that 1 allele had a negative effect of 0.07 percentage points $(P<0.001)$. For the family with 2 positive contrasts, the greater effect was almost 0.11 percentage points $(P<0.001)$. These results may confirm those of Sanders et al. (2006), who found that additional mutations in the DGAT1 gene also affect fat concentration.

All 4 bulls that were analyzed for milk yield had significant $(P<0.05)$ within-family contrasts for both milk yield and fat percentage. For 3 of the 4 bulls, the allele with a negative effect had the greater absolute value compared with the allele with a positive effect; for the other bull, both alleles had a negative effect. Mean negative effect for milk yield was $170 \mathrm{~kg}$ based on the allele with the greatest absolute value. Mean positive effects ranged from 38 to $72 \mathrm{~kg}$ but were not significant $(P>0.05)$. The negative effect on milk yield corresponded to positive effects for both fat yield and fat percentage as well as effects of the QTN located in $D G A T 1$, which affects all 3 traits. In the current study, the bull with greatest positive effect for fat percentage also had the greatest negative effect for milk yield.

Application of the modified granddaughter design likely was premature, because only 18 bulls had $>200$ granddaughters with a record usable for genetic evaluation. Because of the relatively low reliability of traditional genetic cow evaluations, and the fact that these cows were not a random sample, within-family effects for samples of this size are not likely to be significant $(P<0.05)$. Currently, 147,761 Holstein females with listed grandsires have been genotyped, but most of those females are calves without their own production or conformation records. The modified granddaughter design should be reapplied to this population in approximately $2 \mathrm{yr}$ when much larger data sets will be available.

\section{CONCLUSIONS}

For 33 traits analyzed with an APGD, within-family haplotype had an effect $(P<0.01)$ for all but 2 traits. Complete concordance was not obtained for any of the traits analyzed either with or without adjustment for SNP effects on other chromosomes. Of the 31 traits with effects $(P<0.01)$ for the APGD, only 21 could be analyzed for the modified granddaughter design. Of those traits, 8 had significant $(P<0.01)$ withinfamily haplotype effects. With respect to milk and fat yields and fat percentage, the results on BTA 14 corresponded to the hypothesis that a missense mutation in $D G A T 1$ is the main causative mutation, although other polymorphisms in that gene also modify fat yield and percentage. The positive allele for protein concentration was less frequent, which indicated that selection on that locus could be effective. Although the results can be used to determine causative mutations for most of the analyzed traits, complete DNA sequencing probably will be needed for of most of the analyzed sires. 
In approximately $2 \mathrm{yr}$, a much larger sample of cows will be available for application of the modified granddaughter design.

\section{ACKNOWLEDGMENTS}

This research was supported by a grant from the Binational Agricultural Research and Development (BARD) Fund Research Project IS-4394-11R. The authors thank the Ministero delle Politiche Agricole Alimentari e Forestali (MIPAAF, Rome, Italy) for funding the high-density (HD) genotypes contributed by the Innovagen project (DM 10750-7303-2011) and Department for Environment, Food and Rural Affairs (Defra; London, UK) for funding the HD genotypes contributed as part of the Ruminant Genetic Improvement Network. The authors thank Suzanne Hubbard for editorial assistance.

\section{REFERENCES}

Ashwell, M. S., D. W. Heyen, T. S. Sonstegard, C. P. Van Tassell, Y. Da, P. M. VanRaden, M. Ron, J. I. Weller, and H. A. Lewin. 2004. Detection of quantitative trait loci affecting milk production, health, and reproductive traits in Holstein cattle. J. Dairy Sci. $87: 468-475$.

Cohen-Zinder, M., E. Seroussi, D. M. Larkin, J. J. Loor, A. Everts-van der Wind, J. H. Lee, J. K. Drackley, M. R. Band, A. G. Hernandez, M. Shani, H. A. Lewin, J. I. Weller, and M. Ron. 2005. Identification of a missense mutation in the bovine $A B C G 2$ gene with a major effect on the QTL on chromosome 6 affecting milk yield and composition in Holstein cattle. Genome Res. 15:936-944.

Cole, J. B., P. M. VanRaden, and Multi-State Project S-1040. 2010. Net merit as a measure of lifetime profit: 2010 revision. AIPL Res. Rep. NM\$4(12-09). Accessed Jan. 23, 2013. http://aipl.arsusda. gov/reference/nmcalc-2010.htm.

Cole, J. B., P. M. VanRaden, J. R. O'Connell, C. P. Van Tassell, T. S. Sonstegard, R. D. Schnabel, J. F. Taylor, and G. R. Wiggans. 2009. Distribution and location of genetic effects for dairy traits. J. Dairy Sci. 92:2931-2946.

Cole, J. B., G. R. Wiggans, and P. M. VanRaden. 2007. Genetic evaluation of stillbirth in United States Holsteins using a sire-maternal grandsire threshold model. J. Dairy Sci. 90:2480-2488.

Druet, T., S. Fritz, M. Boussaha, S. Ben-Jemaa, F. Guillaume, D. Derbala, D. Zelenika, D. Lechner, C. Charon, D. Boichard, I. G. Gut, A. Eggen, and M. Gautier. 2008. Fine mapping of quantitative trait loci affecting female fertility in dairy cattle on BTA03 using a dense single-nucleotide polymorphism map. Genetics 178:2227-2235.

Georges, M., D. Nielsen, M. Mackinnon, A. Mishra, R. Okimoto, A. T. Pasquino, L. S. Sargeant, A. Sorensen, M. R. Steele, X. Zhao, J. E. Womack, and I. Hoeschele. 1995. Mapping quantitative trait loci controlling milk production in dairy cattle by exploiting progeny testing. Genetics 139:907-920.

Glick, G., A. Shirak, E. Seroussi, Y. Zeron, E. Ezra, J. I. Weller, and M. Ron. 2011. Fine mapping of a QTL for fertility on BTA7 and its association with a CNV in the Israeli Holsteins. G3 (Bethesda) $1: 65-74$.

Grisart, B., W. Coppieters, F. Farnir, L. Karim, C. Ford, P. Berzi, N. Cambisano, M. Mni, S. Reid, P. Simon, R. Spelman, M. Georges, and R. Snell. 2002. Positional candidate cloning of a QTL in dairy cattle: Identification of a missense mutation in the bovine DGAT1 gene with major effect on milk yield and composition. Genome Res. 12:222-231.
Holstein Association USA. 2012. Linear type evaluations. Accessed Jan. 24, 2013. http://www.holsteinusa.com/genetic_evaluations/ ss_linear.html.

Illumina Inc. 2010. BovineHD Genotyping BeadChip. Accessed Jan. 23, 2013. http://www.illumina.com/Documents/products/datasheets/datasheet_bovineHD.pdf.

Illumina Inc. 2011. BovineSNP50 Genotyping BeadChip. Accessed Jan. 16, 2013. http://www.illumina.com/Documents/products/ datasheets/datasheet_bovine_snp5O.pdf.

Kaupe, B., A. Winter, R. Fries, and G. Erhardt. 2004. DGAT1 polymorphism in Bos indicus and Bos taurus cattle breeds. J. Dairy Res. 71:182-187.

Ron, M., E. Feldmesser, M. Golik, I. Tager-Cohen, D. Kliger, V. Reiss, R. Domochovsky, O. Alus, E. Seroussi, E. Ezra, and J. I. Weller. 2004. A complete genome scan of the Israeli Holstein population for quantitative trait loci by a daughter design. J. Dairy Sci. $87: 476-490$.

Ron, M., and J. I. Weller. 2007. From QTL to QTN identification in livestock-Winning by points rather than knock-out: A review. Anim. Genet. 38:429-439.

Sanders, K., J. Bennewitz, N. Reinsch, G. Thaller, E.-M. Prinzenberg, C. Kühn, and E. Kalm. 2006. Characterization of the DGAT1 mutations and the CSN1S1 promoter in the German Angeln dairy cattle population. J. Dairy Sci. 89:3164-3174.

SAS Institute. 2012. Base SAS ${ }^{\circledR} 9.3$ Procedures Guide. 2nd ed. SAS Institute Inc., Cary, NC.

Van Tassell, C. P., G. R. Wiggans, and I. Misztal. 2003. Implementation of a sire-maternal grandsire model for evaluation of calving ease in the United States. J. Dairy Sci. 86:3366-3373.

VanRaden, P. 2011. findhap.f90. Accessed Jan. 23, 2013. http://aipl. arsusda.gov/software/findhap/.

VanRaden, P., M. Tooker, and G. Fok. 2011. Multitrait heifer and cow conception rates. Changes to evaluation system (April 2011). Accessed Jan. 24, 2013. http://aipl.arsusda.gov/reference/changes/ eval1104.html.

VanRaden, P. M., M. E. Tooker, J. B. Cole, G. R. Wiggans, and J. H. Megonigal Jr. 2007. Genetic evaluations for mixed-breed populations. J. Dairy Sci. 90:2434-2441.

VanRaden, P. M., C. P. Van Tassell, G. R. Wiggans, T. S. Sonstegard, R. D. Schnabel, J. F. Taylor, and F. S. Schenkel. 2009. Invited review: Reliability of genomic predictions for North American Holstein bulls. J. Dairy Sci. 92:16-24.

VanRaden, P. M., and G. R. Wiggans. 1991. Derivation, calculation, and use of national animal model information. J. Dairy Sci. $74: 2737-2746$.

Weller, J. I. 2007. Marker assisted selection in dairy cattle. Pages 199-228 in Marker-Assisted Selection: Current Status and Future Perspectives in Crops, Livestock, Forestry and Fish. E. Guimarães, J. Ruane, B. D. Scherf, A. Sonnino, J. D. Dargie, ed. Food and Agriculture Organization of the United Nations, Rome, Italy.

Weller, J. I., Y. Kashi, and M. Soller. 1990. Power of daughter and granddaughter designs for determining linkage between marker loci and quantitative trait loci in dairy cattle. J. Dairy Sci. $73: 2525-2537$.

Weller, J. I., and M. Ron. 2011. Invited review: Quantitative trait nucleotide determination in the era of genomic selection. J. Dairy Sci. 94:1082-1090.

Weller, J. I., H. Weller, D. Kliger, and M. Ron. 2002. Estimation of quantitative trait locus allele frequency via a modified granddaughter design. Genetics 162:841-849.

Wiggans, G. R., T. A. Cooper, P. M. VanRaden, and J. B. Cole 2011. Technical note: Adjustment of traditional cow evaluations to improve accuracy of genomic predictions. J. Dairy Sci. 94:61886193.

Winter, A., W. Krämer, F. A. O. Werner, S. Kollers, S. Kata, G. Durstewitz, J. Buitkamp, J. E. Womack, G. Thaller, and R. Fries. 2002. Association of a lysine-232/alanine polymorphism in a bovine gene encoding acyl-CoA:diacylglycerol acyltransferase (DGAT1) with variation at a quantitative trait locus for milk fat content. Proc. Natl. Acad. Sci. USA 99:9300-9305. 